\title{
Modeling and Ground Observations of the Ionosphere Related to the COSMIC Project
}

Jann-Yenq Liu ${ }^{1}{ }^{*}$, Yen-Hsyang Chu ${ }^{1}$, Ming-Quey Chen ${ }^{1}$, Lung-Chih Tsai ${ }^{1}$ and Chien-Ming Huang ${ }^{1}$

(Manuscript received 22 February 2000, in final form 2 March 2000)

\begin{abstract}
Ground observations have been used to study the ionosphere by providing electron density profiles and TEC distribution. In this paper, the existing ground and space facilities related to constructing the Constellation Observing System for Meteorology, Ionosphere, and Climate (COSMIC) Project are reviewed. We show that these observations can be employed to validate results derived from COSMIC satellites. In addition, the NCAR TIEGCM model is introduced to simulate ionosphere TEC during year of the solar minimum. The observations and simulations present a clear signature of the equatorial anomaly, in which the TEC shows a minimum on the magnetic equator and a maximum on each side. Meanwhile, it is interesting to see that the value of TEC in June (Day 170) becomes weaker with the crests moving toward the geomagnetic equator.
\end{abstract}

(Key words: Ionosphere, Electron density, TEC, GPS, MIR Space Station, COSMIC, Digisonde, TIEGCM)

\section{INTRODUCTION}

Ionospheric observations and research in Taiwan have been carried out for more than 45 years. Significant contributions to ionospheric physics and probing techniques have been achieved by the local scientists. In 2003, the National Space Program Office (NSPO) of the Republic of China plans to launch eight small low-Earth-orbit (LEO) satellites, each with an altitude of 700 800 km and an inclination angle of $70^{\circ} \sim 80^{\circ}$, and there will form a constellation observing system for meteorology, ionosphere, and climate (COSMIC). This project will both stimulate ionospheric research in Taiwan and allow it to play a leading role in the worldwide scientific community.

Three instruments - the Global Positioning System (GPS) receiver, Tri-Band-Beacon

${ }^{1}$ Institute of Space Science; Center for Space and Remote Sensing Research, National Central University, Taiwan, ROC

* Corresponding author address: Dr. Jann-Yenq Liu, Institute of Space Science; Center for Space and Remote Sensing Research, National Central Univęrsity, Chung-Li, Taiwan, ROC

E-mail: jyliu@jupiter.ss.ncu.edu.tw 
(TBB), and Tiny Ionospheric Photometer (TIP) - will be mounted on each of the COSMIC satellites to observe the atmosphere and ionosphere. The inversion techniques, observations, and applications of the three instruments can be found in the papers of the current issue. Therefore, this paper reviews the ground/space base observations and modeling study related to the COSMIC project, and their applications to the equatorial anomaly ionosphere.

\section{HISTORY}

Ionospheric observation and investigation in Taiwan was initiated in 1951 when a manual ionosonde was first used at National Taiwan University by Prof. Chien Fung. Prof. Fung was a friend of Sir E. V. Appleton and helped him to prove the existence of equatorial anomaly by installing ionospheric sounding equipment in Chungking in mainland China. The routine observation of the ionosphere in Taiwan was started in 1952 by the Radio Research Laboratory (RRL) of the Ministry of Communication. In 1960 with the help of the Central Radio Propagation Laboratory of the National Bureau of Standard of the U.S.A, the manual ionospheric sounder was replaced by an automatic ionospheric sounder of the C2 model. In 1966 the ionospheric sounding station was moved from Taipei to Chung-Li, about $40 \mathrm{~km}$ southwest of Taipei, due to the increase in environmental noise, and the $\mathrm{C} 2$ sounder was upgraded to a $\mathrm{C} 2 / \mathrm{C} 4$ model. Although RRL was reorganized and renamed as the Telecommunication Laboratory in 1969, the ionospheric routine observations made by the Chung-Li sounding station have continued without interruption. In 1984 the $\mathrm{C} 2 / \mathrm{C} 4$ sounder was further replaced by an IPS-42 ionosonde with a digital sampling function. Since then, the IPS-42 ionosonde has been used for routine soundings. Usually the observations are made every 15 minutes. The characteristics of the ionosphere have been routinely reduced in accordance with the "URSI Handbooks of Ionogram Interpretation and Reduction". In 1994, a laboratory-type advanced ionospheric sounder, digisonde portable sounder (DPS), was set up on campus by National Central University (NCU). The DPS provides ionospheric parameters for the echo amplitude, echo polarization, virtual height, echolocation, Doppler velocity, and electron density profile for ionospheric studies.

The capability of observing ionospheric total electron content (TEC) in Taiwan was first established in 1969 by measuring the Faraday rotation angle of VHF beacon signals transmitted from IIF-2 and IIF-3 geostationary satellites. With the help of the U.S. Air Force Cambridge Research Laboratory, the long term observation of ionospheric TEC was started in January 1976 at Lunping Observatory by receiving the VHF beacon signal from INTELSAT. However, the observation was discontinued in August 1976 because the satellite drifted out of the viewing region of Observatory. The TEC observation was resumed in March 1977 when the VHF beacon signal from the Japanese ETS-2 geostationary satellite became available. In addition to the geostationary satellite, in 1984 the measurement of TEC by means of the technique of differential Doppler frequency shifts of 150 and $400 \mathrm{MHz}$ coherent radio waves from U.S. Navy Navigation Satellite System was also established. The scintillation and/or depletion of TEC may occur if the path of radio wave between satellite and ground-based receiver contains electron density irregularities. Therefore, the behavior of ionospheric irregularities can be studied using the phenomena of scintillation and depletion of TEC. Liu et al. (1996) 
introduced a procedure to derive the ionospheric TEC from measurements of the Global Positioning System (GPS) receivers.

\section{ELECTRON DENSITY PROFILE}

Most of our knowledge of the ionosphere comes from remote sensing by radio waves. The conventional equipment for measuring the virtual height of the ionosphere is a sweepfrequency pulsed radar device called an ionosonde. The measurement of the frequency virtual height variation of the ionosphere obtained by an ionosonde is called an ionogram.

An ionogram displays the variation of the virtual height of reflection with frequency, where the virtual height is equivalent to one-half the time-of-flight of the transmitted radio wave times the speed of light c. However, a vertically incident radio wave pulse is affected by the ionospheric refractive index $\mu$ and travels upwards with a group velocity $u=\mu \mathrm{c}$, until it is reflected at some height $h_{\vartheta}$, where $\mu=0$, and returns to the ground. The height $h_{0}$ is called the "true height" (or "real height") of the reflection. Note that at ground level the true height $h=0$ and the refractive index $\mu=1$. The relation between the virtual height and the true height is given by:

$$
h^{\prime}(f)=\int_{0}^{h_{0}(f)} \mu^{\prime}(N, B, f) d h,
$$

where $h^{\prime}$ and $f$ represent the virtual height of reflection and the frequency of radio waves; $\mu^{\prime}=1 / \mu$ is the group refractive index; $N$ and $B$ are the electron density and geomagnetic field strength, respectively, at a certain true height $h$.

Electron density profiles can provide detailed information about the variation of the ionosphere and the effect of those variations on radio wave propagation. From the AppletonHartree formula (see Buden, 1985) and the integral equation (1), it can be seen that the behavior of virtual heights displayed in an ionogram are not consistent with the true distributions of the ionspheric electron density. Therefore, it is desirable for the scientist in the ionospheric community to obtain the vertical structure of electron density retrieved from the virtual height. Three existing true height analysis routines PLOAN (Tritheridge, 1985), Polynomial Fitting (Tsai et al., 1995) and ARTIST (Reinisch, 1996) are available to derive electron density true height profiles. A true height profile can be compared with a co-located electron density profile simultaneously obtained from the GPS receivers of the COSMIC satellite. Figure 1 shows a typical ionogram obtained during the night by the Digital Portable Sounder (DPS) at National Central University, in which the discrete curves marked by red and green dots are, respectively, the traces of ordinary and extraordinary waves. As indicated, the virtual height of the $\mathrm{F}$ region is about $240 \mathrm{~km}$ and a salient sporadic E layer located at an altitude of about 100 $\mathrm{km}$ is also observed.

\section{THE GPS/MET PROFILE}

The GPS receivers mounted on the COSMIC satellites receive the signals transmitted from the GPS satellites orbiting the Earth at an altitude of approximately $21,000 \mathrm{~km}$. The 


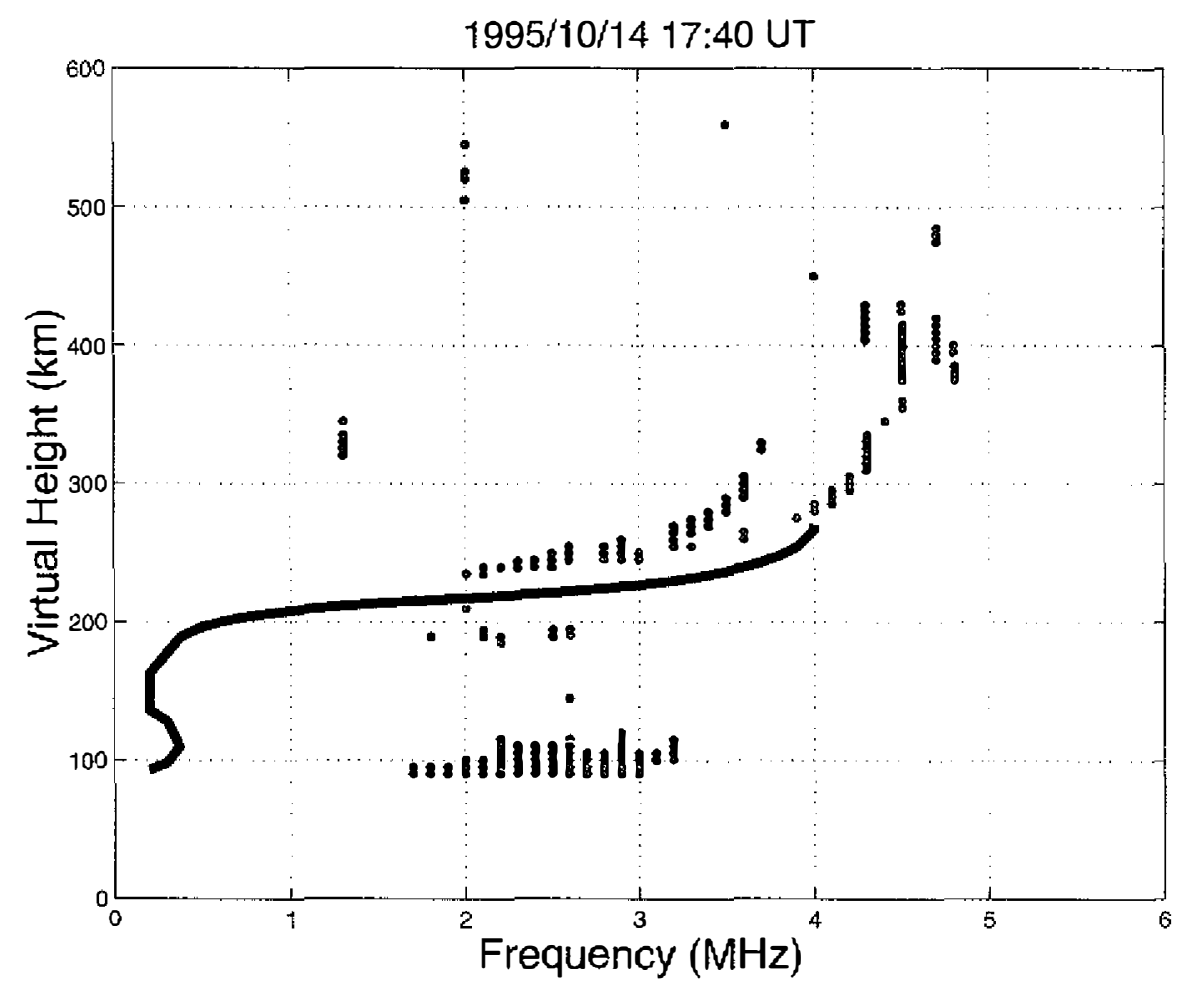

Fig. l. A typical ionogram observed by NCU DPS at $0139 \mathrm{LT}$ on 15 October 1995.

occultations occur as the COSMIC satellites rise or fall relative to the GPS satellites. Under these circumstances, the GPS signals received by COSMIC satellites are bent at a small angle as they passe through the terrestrial atmosphere. The refractive index of the atmosphere can be retrieved from the bending angle via the Abel integral transformation under the appropriate assumptions (for details, see Hajj et al., 2000). Once the atmospheric refractivity has been obtained, the profiles of pressure, temperature, humidity, and the ionospheric electron density at about $200 \mathrm{~m}$ height resolution and about $300 \mathrm{~km}$ horizontal resolution, can be calculated. The Global Positioning System/Meteorology (GPS/MET) Program is the first experiment using a low Earth orbiting (LEO) satellite (MicroLab l) to receive Multi-channel GPS signals, which demonstrate active limb sounding of the Earth's atmosphere and ionosphere by radio occultation techniques. Figure 2 shows the plots of electron density profiles acquired at 0139 LT on 15 October 1995 from GPS/MET data and ionograms recorded by the NCU DPS. The profiles of the lower part of the ionosphere obtained by the two techniques generally yield a similar tendency. The difference between the two might result from asymmetry structure in the equatorial anomaly region for the occultation reconstruction and errors in the true height analysis.

The upper part of the electron density profile cannot be observed using ionosonde, and therefore requires another kind of sounding technique, such as incoherent scattering radars or 


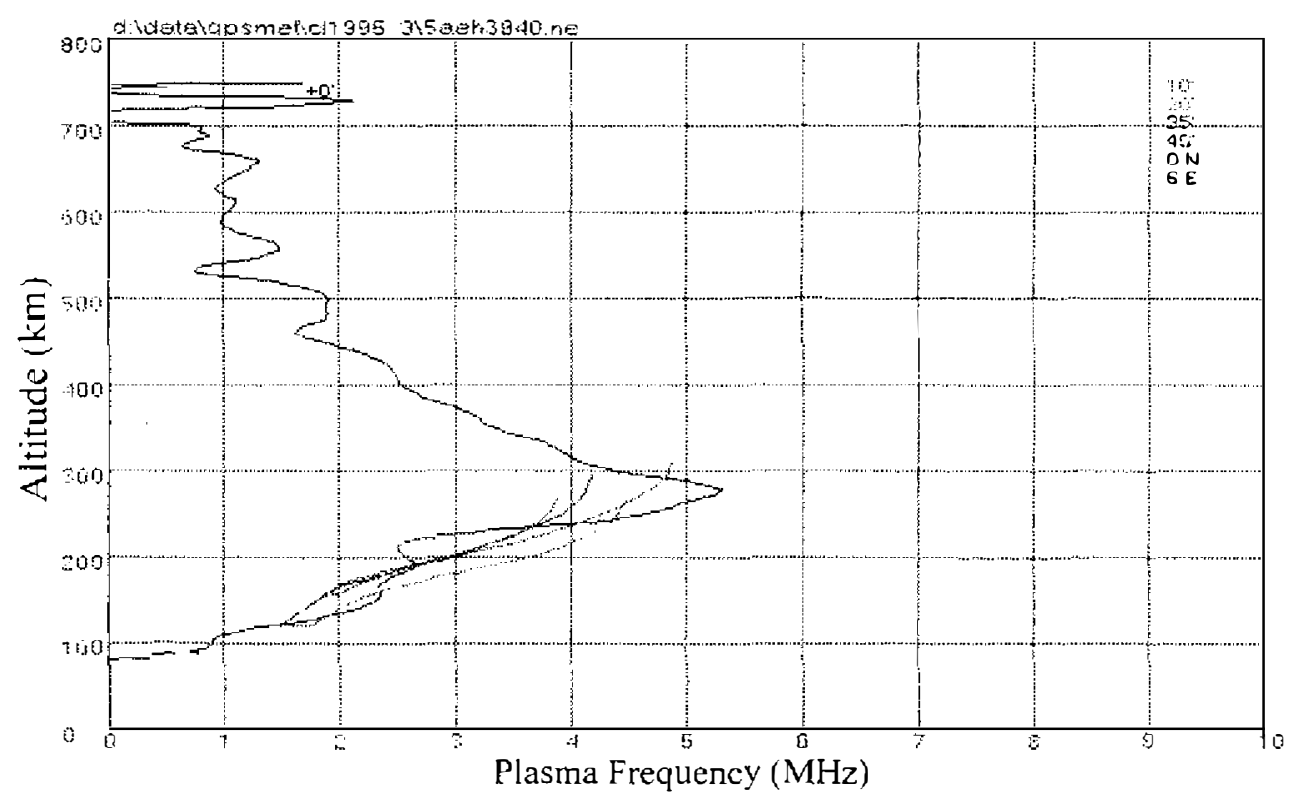

Fig. 2. Comparisons of ionospheric plasma density profiles obtained by GPS/ MET occultation measurements (shown in blue color) using Abel inversion through TEC and from true-height analysis for ionograms (shown in other colors) recorded by the Chung-Li Digisonde at 0139 LT on 15 October 1995. The upper right-hand corner shows the ionogram recording time differences to the referred occultation measurement and the position difference (in degrees) from the coordinate of the impact point with maximum electron density by GPSMET occultation measurements to the Chung-Li Digisonde site $\left(24.6^{\circ} \mathrm{N}, 121.0^{\circ} \mathrm{E}\right)$.

topside sounder. Since there are no incoherent scattering radars in the Taiwan area, topside sounders are the most suitable apparatus for validating the upper part of the electron density acquired by GPS/MET and COSMIC satellites. The most recent experiment on the upper part of the density profile was carried out using a topside sounder on the MIR space station. The first test passes were received at the Institute of Space Science, National Central University, Chung-Li, Taiwan, on 21 April 1999 (Fig. 3). A sequence of the topside ionograms has been obtained and the two closest to Chung-Li satellite ionograms are presented in Fig. 4. The signal amplitude is color coded, with the horizontal axis representing the sounding frequency and the vertical one the virtual height calculated downwards from the satellite height. The presence of the groundbased DPS vertical sounder gave the wonderful opportunity to reconstruct the total vertical profile of electron concentration from the ground to space station height, including the most interesting main maximum of the electron concentration. The corresponding bottomside ionograms are presented in Fig. 5. Taking into account the difference in longitude (local time), the critical frequencies practically coincide, which confirms the validity of the topside sounding technique. The precision of peak height determination from topside 
IIR Orbital station Passes Received at Chung-Li

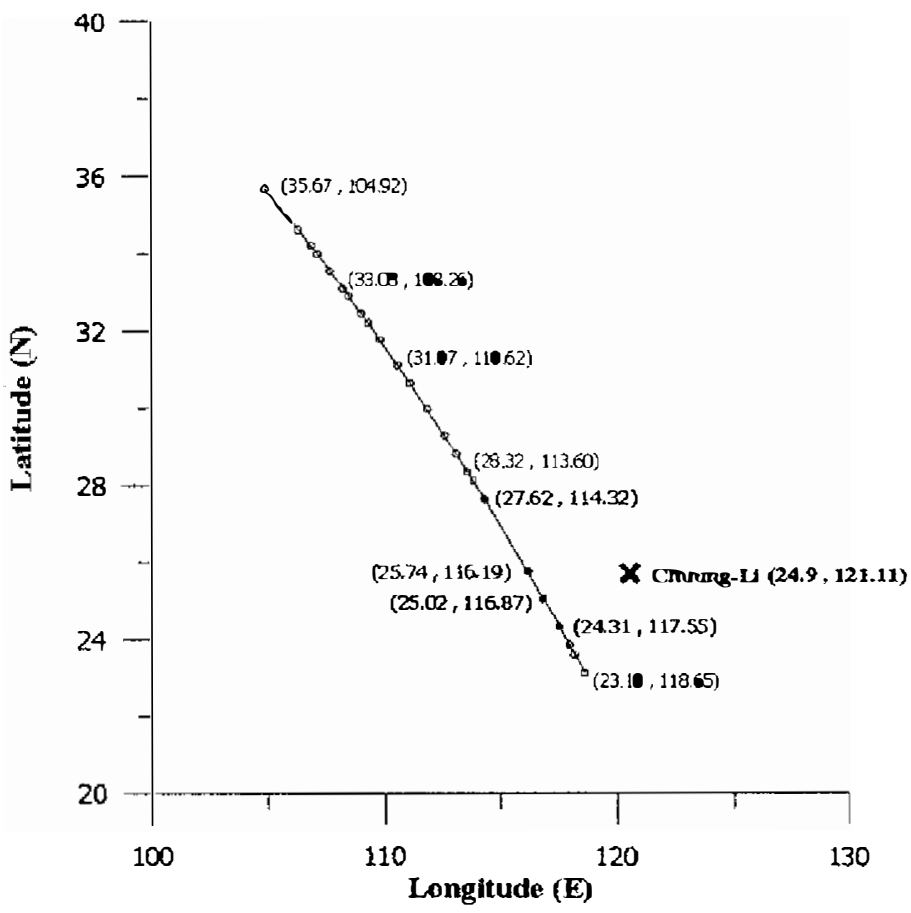

Fig. 3. Cartesian projections (geodetic latitudelongitude) of the MIR station orbits received at Chung-Li.

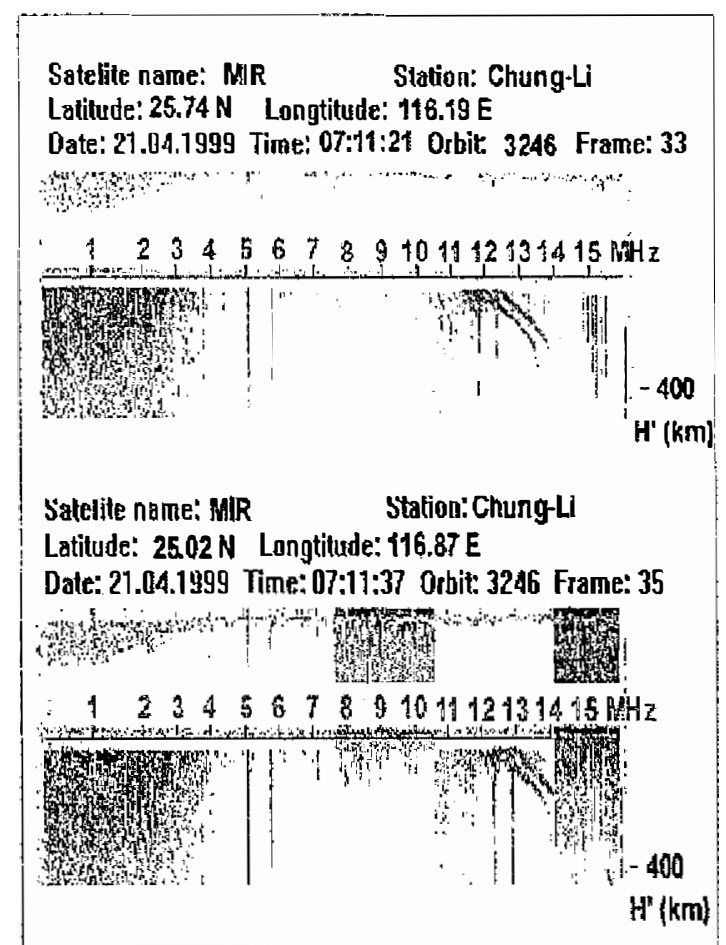

Fig. 4. The topside ionograms selected for comparison with groundbased sounding data. 

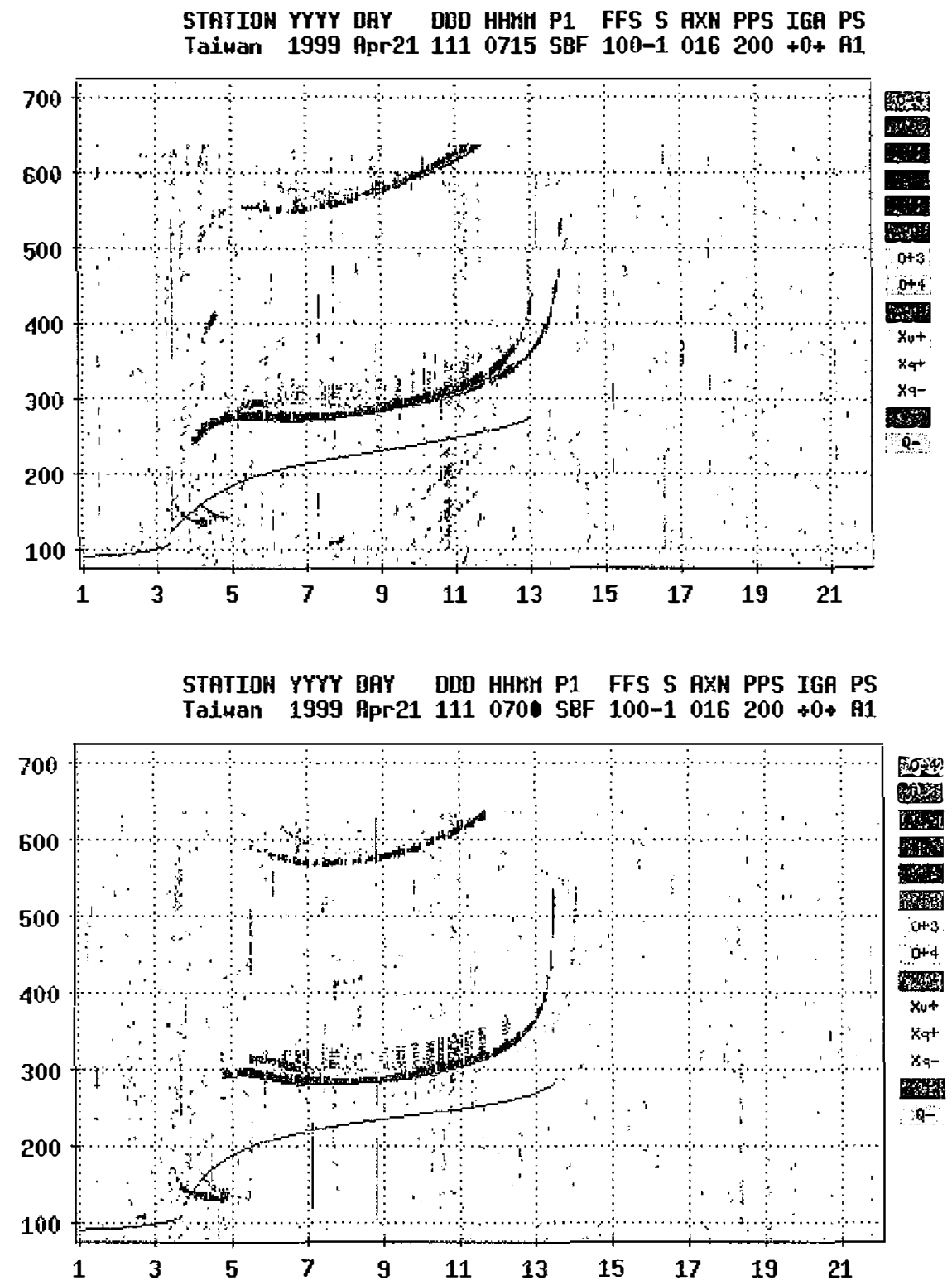

Fig. 5. Bottomside ionograms obtained during MIR station pass on 21 April 1999

ionograms is still subject to discussion. The MIR station gives the perfect opportunity to check the validity of topside profiles calculation algorithm because of two factors: a) the low altitude of the MIR station orbit makes the profiles short and calculations more simple and precise; b) again due to the low altitude sometimes the station will fall directly into the peak of electron concentration, and hence the peak height and peak electron density could be deter- 
mined from the in situ measurements. This situation occurred twice during MIR station passes received at Chung-Li.

Taking into account the above discussion, it is interesting to compare the calculated topside and bottomside vertical profiles of electron concentration. For this purpose the topside profile measured by MIR close to the latitude of Chung-Li $\left(24.9^{\circ} \mathrm{N}\right)$ was selected. The latitude of the MIR station during the sounding for comparison was $25.1^{\circ} \mathrm{N}$. The composed topside-bottomside profiles are presented in Fig. 6. The topside profile calculation was made using the improved Jackson algorithm of topside profile reconstruction (Jackson, 1969). One can see the perfect coincidence in peak electron concentration observed by both techniques. We can regard this comparison as a check-point and further use the topside profiles both to determine the electron concentration and peak height values along the station pass and to determine the equatorial anomaly shape and the crest position.

\section{ELECTRON DENSITY MAP}

The GPS consists of 24 satellites evenly distributed in 6 orbital planes around the globe at an altitude of about $20200 \mathrm{~km}$. The observables depend on the satellite-receiver distance, tropospheric/ionospheric effects, satellite and receiver clock offsets and phase ambiguities, as well as satellite and receiver instrumental biases. There will be a bias for each of the two GPS frequencies ( $\mathrm{fl}=1575.42 \mathrm{MHz}$ and $\mathrm{f} 2=1227.60 \mathrm{MHz}$ ) and their difference, henceforth referred to as differential instrumental bias, produces systematic instrumental errors in the estimates of ionospheric delays. These differential instrumental biases must be removed (Sardon et al., 1994) in order to obtain accurate estimates of the ionospheric TEC.

The propagation of GPS signals is affected by both the environment and instruments.

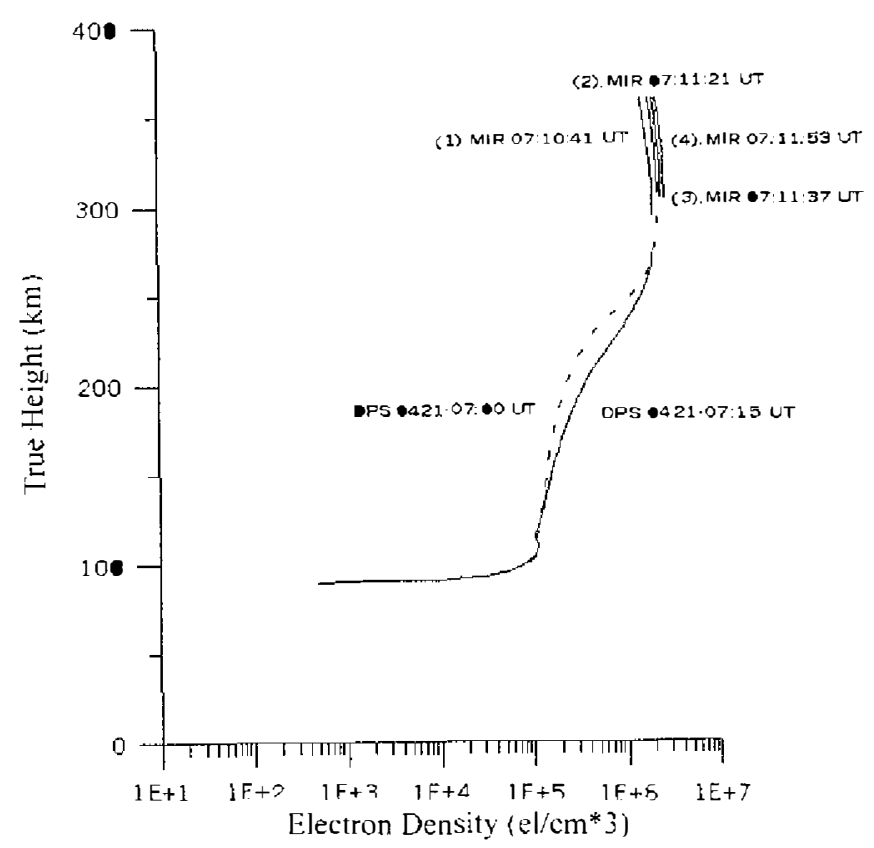

Fig. 6. Topside and bottomside of electron densities derived by the MIR station and NCU DPS. 
Therefore, GPS pseudorange $\mathrm{P}_{k j}^{i}$ and carrier phase $\mathrm{L}_{k j}^{i}$ for frequencies 1 and 2 , in range units, can be expressed as follows:

$$
\begin{gathered}
P_{1, j}^{i}=s_{0, j}^{i}+\boldsymbol{d}_{i o n, 1, j}^{i}+\boldsymbol{d}_{t r o p, j}^{i}+c\left(\tau^{i}-\tau_{j}\right)+\boldsymbol{d}_{q, 1}^{i}+\boldsymbol{d}_{q, 1, j}+\boldsymbol{d}_{r e s, j}^{i}, \\
P_{2, j}^{i}=s_{\bullet, j}^{i}+\boldsymbol{d}_{i m n, 2, j}^{i}+\boldsymbol{d}_{r o p p, j}^{i}+c\left(\tau^{i}-\tau_{j}\right)+\boldsymbol{d}_{q, 2}^{i}+\boldsymbol{d}_{q, 2, j}+\boldsymbol{d}_{r e s, j}^{i}, \\
L_{1, j}^{i}=\lambda_{1} \phi_{1, j}^{i}=s_{0, j}^{i}-d_{i o n, 1, j}^{i}+\boldsymbol{d}_{r o p p, j}^{i}+c\left(\tau^{i}-\tau_{j}\right)-\lambda_{1} b_{1, j}^{i}, \\
L_{2, j}^{i}=\lambda_{2} \phi_{2, j}^{i}=s_{0, j}^{i}-\boldsymbol{d}_{i o n, 2, j}^{i}+\boldsymbol{d}_{t r o p, j}^{i}+c\left(\tau^{i}-\tau_{j}\right)-\lambda_{2} b_{2, j}^{i} .
\end{gathered}
$$

The subscripts $i$ and $j$ represent the satellite and ground-based GPS receivers, respectively, $\mathrm{s}_{0}$, the true distance between the receiver and satellite;

$\mathrm{d}_{\text {ion }}, \mathrm{d}_{\text {trap }}$, the ionospheric and tropospheric effects;

$c$, the speed of light in free space;

$\tau$, the satellite or receiver clock offset;

$\mathrm{d}_{\mathrm{q}}$, the instrumental bias of the satellite or receiver;

$\mathrm{d}_{\text {res }}$, other bias;

$\lambda$, the carrier wavelength;

$\phi$, the total carrier phase between the receiver and satellite; and

$\mathrm{b}$, the cycle slips of the carrier phase.

The ionosphere acts as a dispersive medium for the GPS signals, but the troposphere is nondispersive. As such the tropospheric effect in the carrier phase and pseudorange can be removed by subtracting (2a) from (2b) and (2c) from (2d), respectively. According to the Appleton formula (for an example see Budden, 1985) the phase refractive index $n$ in the ionosphere is a function of the radiowave frequency, electron concentration (or plasma frequency), collision frequency and geomagnetic field strength (or gyrofrequency). In fact, however, the GPS radiowave and plasma frequencies are much greater than the other two. Hence, the ionospheric effect in terms of the total electron content along a line-of-sight, TEC* in electron/ $\mathrm{m}^{2}$, between ground receiver $R_{x}$ and the satellite $T_{x}$ can be written as

$$
\boldsymbol{d}_{i m n}=s^{\prime}-s_{0}=\int_{R_{x}}^{T_{x}}\left(n_{s}-1\right) d l=\frac{40.3}{f^{2}} \int_{R x}^{T_{x}} N d l=\frac{40.3}{f^{2}} T E C^{\hat{x}},
$$

where $\mathrm{dl}$ is the infinitesimal length of the path of the radiowave propagation, $\mathrm{s}^{\prime}$ is the virtual distance between the receiver and satellite, $\mathrm{N}$ is the electron concentration in electron $/ \mathrm{m}^{3}$, and $\mathrm{f}$ represents radiowave frequency in $\mathrm{Hz}$. Substituting (3) into (2a), (2b), (2c), and (2d) yields

$$
\begin{aligned}
& T E C^{*}=\frac{1}{40.3} \frac{f_{1}^{2} f_{2}^{2}}{f_{1}^{2}-f_{2}^{2}}\left(P_{2, j}^{i}-P_{1, j}^{i}-k^{i}-k_{j}\right), \text { and } \\
& T E C^{*}=\frac{1}{40.3} \frac{f_{1}^{2} f_{2}^{2}}{f_{1}^{2}-f_{2}^{2}}\left(\lambda_{1} \phi_{2, j}^{i}-\lambda_{2} \phi_{2, j}^{i}+A_{j}^{i}\right),
\end{aligned}
$$


where $k^{i}=d_{q, 2}^{i}-d_{q, 1}^{i}, \quad k_{j}=d_{q, 2, j}-d_{q, 1, j}$ and

$$
A_{j}^{i}=\left(P_{2, j}^{i}-P_{1, j}^{i}\right)+\left(\lambda_{2} \phi_{2, j}^{i}-\lambda_{1} \phi_{1, j}^{i}\right)-\left(k^{i}-k_{j}\right) \text {. }
$$

Wilson et al. (1992) and Sardon et al. (1994) found ki to be about 2-3 nanoseconds which leads to a value as small as $8 \times 10^{16}$ electron $/ \mathrm{m}^{2}$. Nevertheless, two tables given by Wilson et al. (1992) and Sardon et al. (1994) were employed to redeem the bias of $k_{i}$. To determine $k_{\text {, }}$, Tsai (1995) applied (4) to the measurements from a generic GPS receiver to obtain the TEC and then compared it with the simultaneous data recorde by the local TECMETER during 0400-0500LT (Ezquer et al., 1992). In doing so, he found that the value of $k_{j}$ for each GPS receiver is nearly constant. Although (4) can solely and directly derive the TEC, due to the length of the pseudo code, the precision of the TEC* is relatively low. The alternative way is to combine (4) and (5) to obtain the least-square-fit value of $\mathrm{A}_{\mathrm{j}}^{\mathrm{i}}$, and then to utilize (5) to attain greater precision of the TEC*.

As a LEO satellite passes from the horizon to zenith, the TEC* can be obtained as mentioned above. However, it has been found that it is useful to mathematically adjust the TEC*: to the TEC observed at the subionospheric point which is referred to as the vertical total electron content, VTEC:

$$
\mathrm{VTEC}=\mathrm{TEC} * \mathrm{~S}(\mathrm{e})
$$

In (7), $\mathrm{S}(\mathrm{e})$ is the slant function given by Sover and Fanselow (1987):

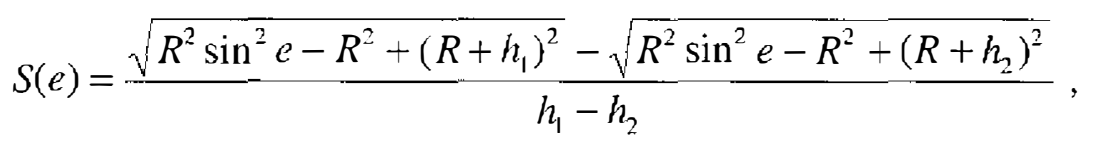

where $e$ is the satellite elevation, $h_{1}$ and $h_{2}$ are, respectively, the lower and upper heights of the ionosphere, and $\mathrm{R}$ is the mean radius of the Earth. It should be noted that the function $\mathrm{S}$ basically depends on the height of the mean layer of the ionosphere, $h_{n 1}=\left(h_{1}+h_{2}\right) / 2$. Davies (1990) indicated that $h_{m}$ could lie between 300 and $450 \mathrm{~km}$, while Holfmann-Wellenhof et al. (1992) considered it should be limited between 300 and $400 \mathrm{~km}$. For simplicity, Sardon et al. (1994) assumed $h_{m}$ to be $355 \mathrm{~km}$. Based on the results in Wu (1992), the present authors find $\mathrm{h}_{\mathrm{m}}$ in the Taiwan area during 1993 and 1994 to be about $325 \mathrm{~km}$. In total, forty to sixty VTECs can be obtained for a network with 8 ground GPS receivers operating simultaneously (5-8 VTECs for each ground site). Accordingly, such a network can ultimately be capable of making a "snapshot" (scan) of the longitudinal/latitudinal (time/latitudinal) TEC distribution in the Taiwan area, thereby constructing a TEC map.

A sequence of the snapshot of the TEC maps with a 30-sec time resolution was produced. Figure 7 shows the latitudinal distributions of the electron density and TEC respectively, as deduced by the MIR space station and the ground based GPS network, yield an excellent agreement.

To study the behavior of the development of the equatorial anomaly crests, the time and latitudinal distribution of the ionospheric TEC was considered. Two ground-based GPS stations, YMSM $\left(25.2^{\circ} \mathrm{N}, 121.6^{\circ} \mathrm{E} ; 14.0^{\circ} \mathrm{N}\right.$ geomagnetic $)$ and DGAR $\left(7.3^{\circ} \mathrm{S}, 72.4^{\circ} \mathrm{E} ; 16.2^{\circ} \mathrm{S}\right.$ geomagnetic) were employed to observe the variations of northern and southern equatorial anomaly regions, respectively. To minimize time shift and neglect unwanted errors, the cut- 
off elevation angle for each GPS receiver were set at $20^{\circ}$.

Figures 8 and 9 illustrate the monthly contour charts of YMSM and DGAR from January to December 1997, respectively, where $1 \mathrm{TECu} \equiv 10^{16} \mathrm{~m}^{-2}$. These figures show the month-tomonth variations in magnitude and locations of the equatorial anomaly crests. Figure 8 illustrates how the minimum values of the equatorial anomaly crest appear in January and July, while the maximum values appear during March-May and October-December. Note that the chart of YMSM in December 1997 may not be very reliable due to the small number of data points recorded. Nevertheless, in general it can be seen that the location of the crests moves northward as the magnitude becomes stronger. The variations of the TEC value in Fig. 9 are almost the same as those in Fig. 8 but the location of the crests shown in Fig. 9 moves northward as the magnitude of TEC becomes weaker, especially during June-August.

\section{MODELING STUDY}

The NCAR TIEGCM is a well-known general circulation model most recently described by Richmond et al. (1992) and references therein. This model is a three-dimensional timedependent model which self-consistently calculates the coupled thermosphere and ionosphere, including electric potential, fields, and currents. It solves the density of major constituents $\left(\mathrm{N}_{2}, \mathrm{O}_{2}\right.$, and $\left.\mathrm{O}\right)$ as well as some minor constituents $\left(N\left({ }^{2} \mathrm{D}\right), N\left({ }^{4} \mathrm{~S}\right)\right.$, and $\left.N \mathrm{O}\right)$, as well as solving

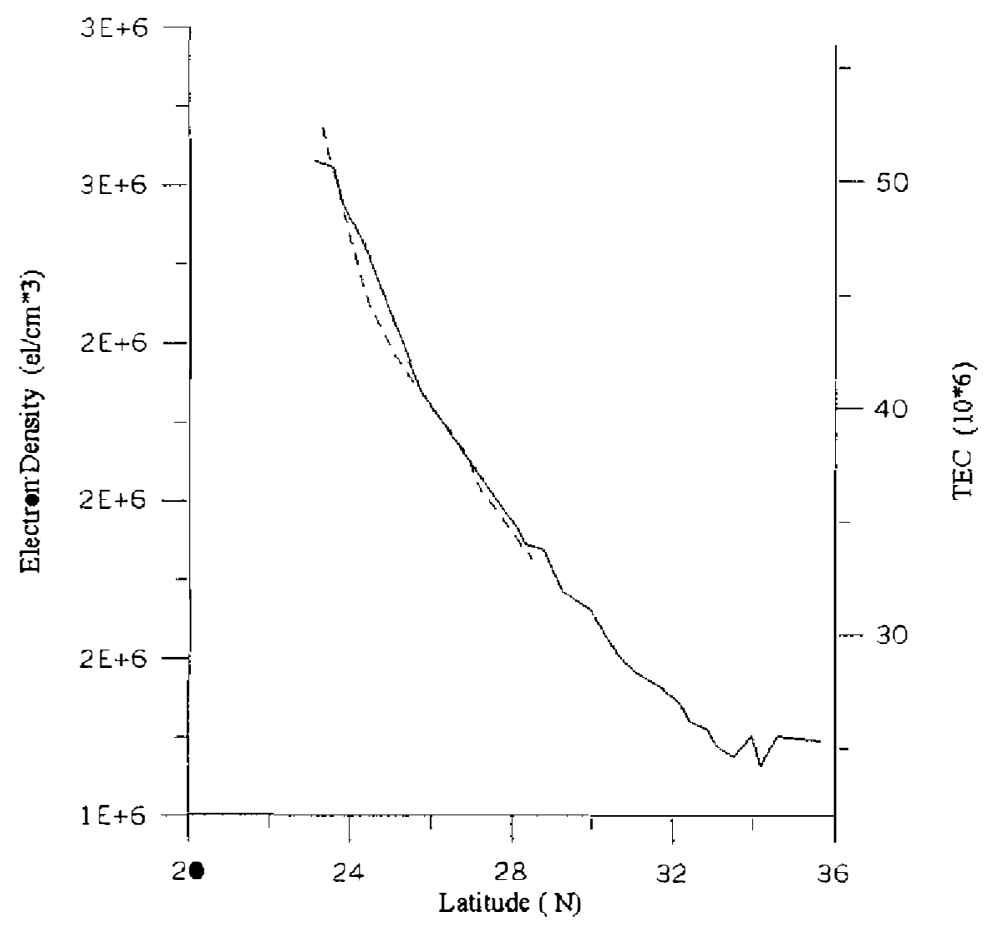

Fig. 7. The electron density and TEC, respectively, deduced by the MIR space station and the ground based GPS network at 0710 UT on 21 April 1999. 

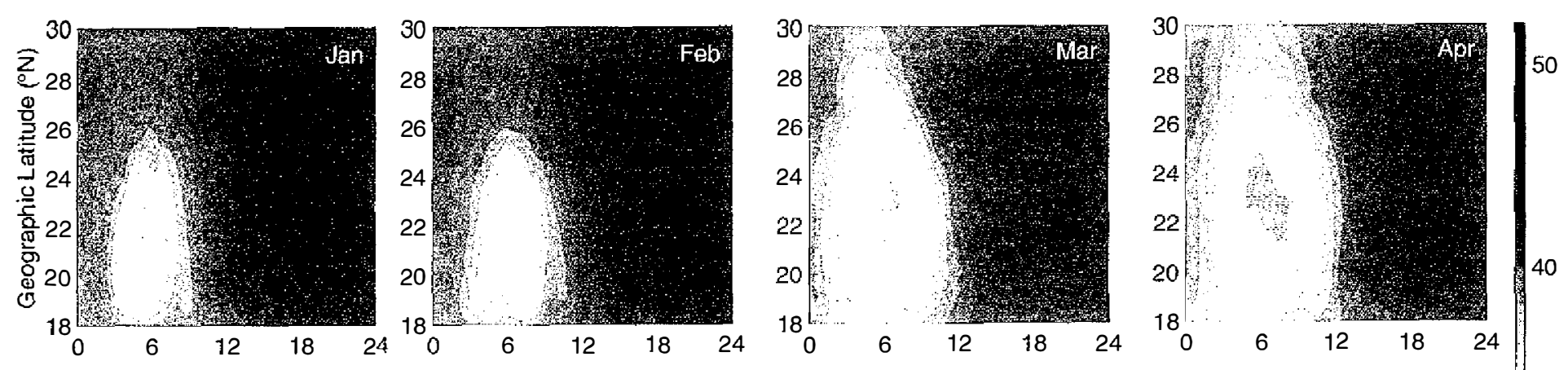

$\stackrel{\omega}{8}$
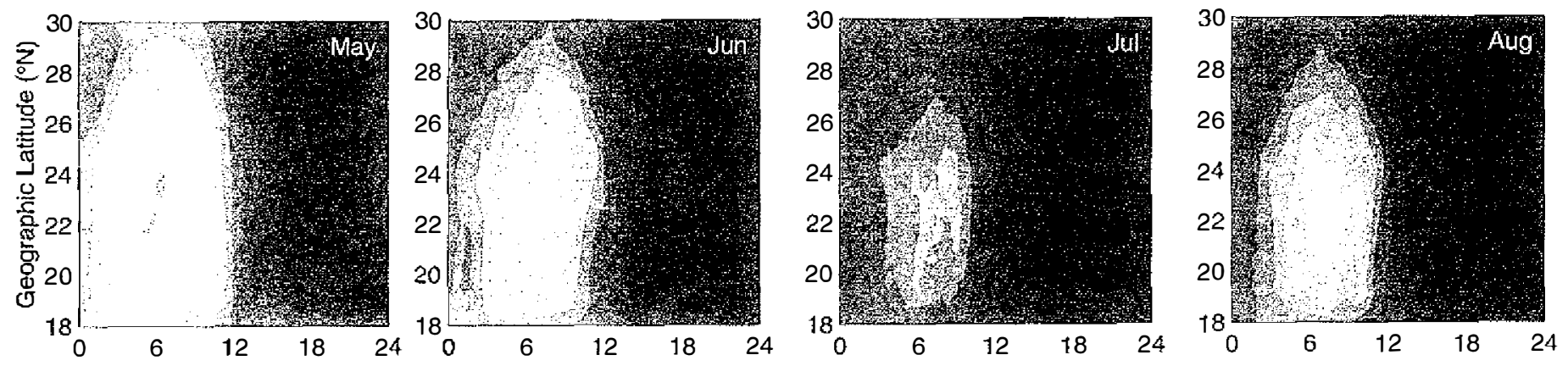

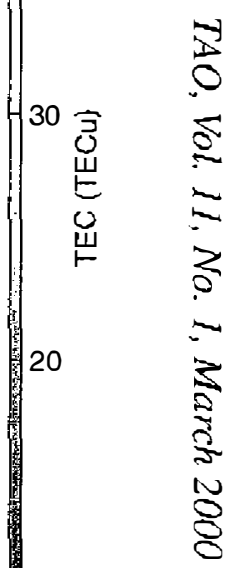
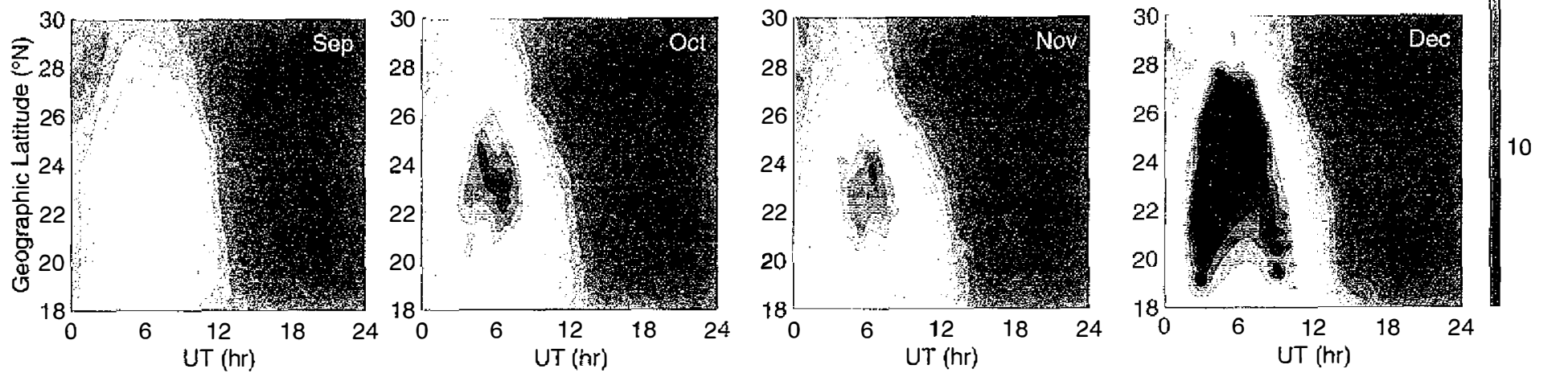

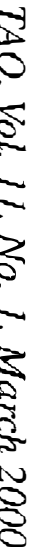

Fig. 8. The monthly smoothed contour charts of TEC in the northern equatorial anomaly region observed by YMSM in 1997. 

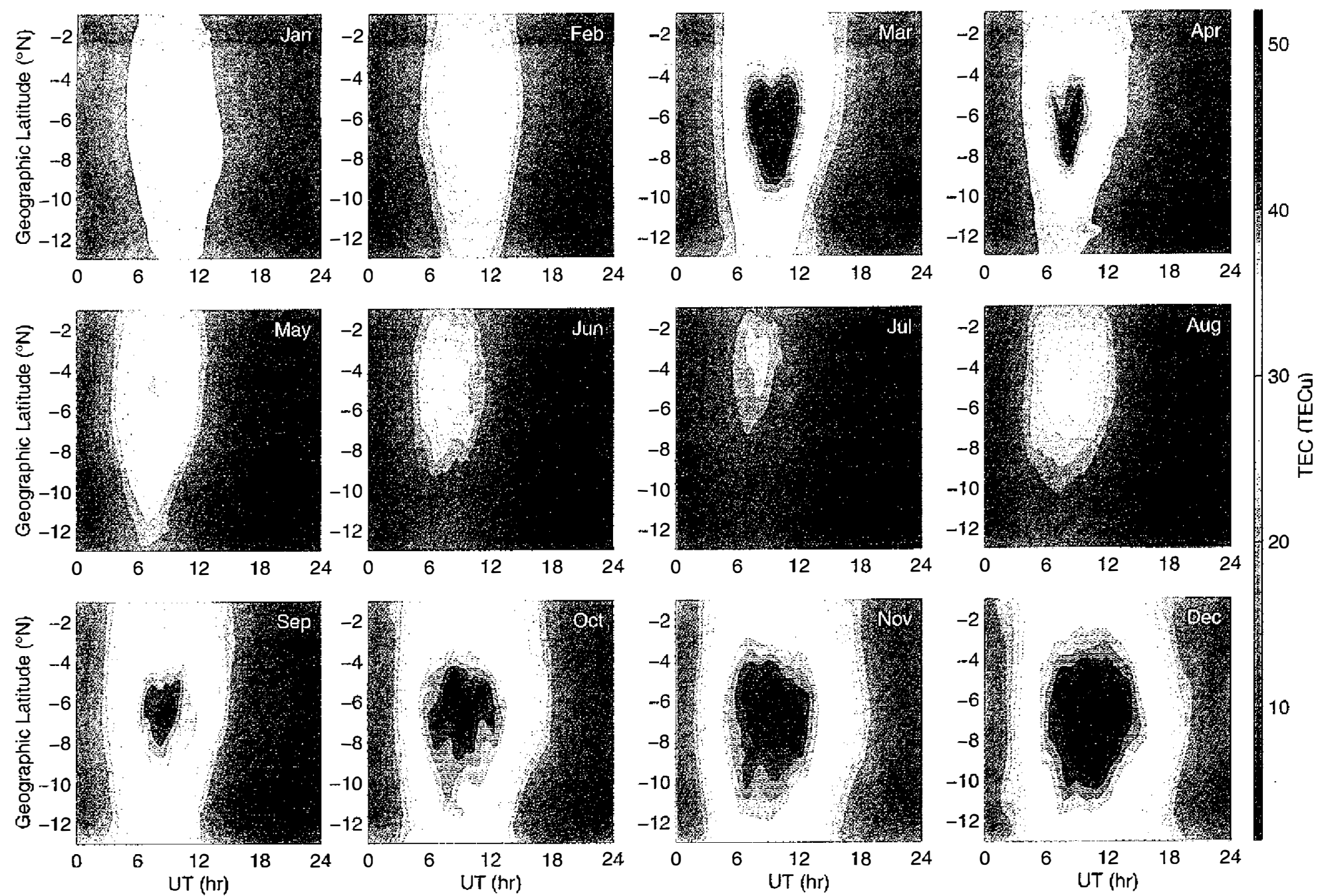

5
5
5
5
5

Fig. 9. The monthly smoothed contour charts of TEC in the southern equatorial anomaly region observed by DGAR in 1997. 
the densities of electron and ions $\left(\mathrm{O}^{+}, \mathrm{O}_{2}^{+}, \mathrm{N}_{2}^{+}, \mathrm{N}^{+}, \mathrm{NO}^{+}\right)$. The neutral zonal and meridional winds, the ion drift, and the electron, ion and neutral temperatures are also computed among other fields.

The model uses an Eulerian approach to solve for the structure of the thermosphere and the ionosphere. Two grid systems are required: one in geographical coordinates with $36 \times 72$ grid points in horizontal directions (in the range -90 to 90 degrees North and -180 to 180 degrees East) and 29 constant pressure levels (from $\mathrm{ZP}=-7 \mathrm{ZP}=+7$, where $\mathrm{ZP}=\ln \left(P_{0} / P\right), P_{0}$ is a reference pressure of $50 \mu \mathrm{Pa}$ and $P$ is pressure) in vertical extending from approximately 95 to $600 \mathrm{~km}$; the other one in geomagnetic horizontal coordinates with $96 \times 80$ grid points.

The input parameters of the global model are the solar UV, EUV radiation, the auroral precipitating particle flux, the electric potential in the polar caps, and, at the lower altitude boundary, the upward propagating atmospheric tides into thermosphere. The model represents the effects of the diurnal $(1,1)$ mode and the semidiurnal $(2,2),(2,3),(2,4),(2,5)$, and $(2,6)$ modes (e.g., Fesen et al., 1991; Forbes et al., 1993). All the input parameters in the model are adjustable so that the model can simulate the thermosphere and ionosphere in different space weather conditions.

A quick run of the TIEGM model was carried out to examine the total electron contents during geomagnetic quiet time were done for solar cycle minimum conditions (see Fig. 10) which allow us compare with the results obtained by the YMSM and DGAR GPS receivers. Figure 10 shows the slab electron contents in various altitude ranges during March (Day 80), June (Day 170), September (Day 260), and December (Day 350). The clearest crest structures appear at the 300-350 km slab electron contents. It can be fund that in June (Day 170), the magnitude of the TEC becomes weaker and the crest moves toward the geomagnetic equator. This generally agrees with the observation from YMSM and DGAR.

\section{SUMMARY}

The ground observations of ionosphere related to the COSMIC Project in. Taiwan are reviewed. Instead of technical developments, we apply the existing techniques to deduce the vertical and horizontal electron density distributions. It is found that bottom/topside ionosonde observations can be employed to validate the vertical density profiles derived by GPS/MET and COSMIC satellites. Regional and global networks of the ground based GPS receivers are useful to check the horizontal structures of the ionospheric electron density and the TEC observed by the GPS/MET satellite. A suitable ionospheric model, such as TIEGCM, provides information on electric potential, fields, currents, atmospheric constituents, electron and ion density, neutral winds, plasma drift, temperatures, among others. The 3-D distribution of electron density can also be obtained from the data estimated by COSMIC GPS occultation in the ionosphere using tomography techniques. Comparisons between COSMIC observations and modeling studies provide an understanding of the structure and dynamics in the ionosphere.

Acknowledgments This research was supported by the National Science Council under grant no. NSC 88-NSPO(B)-RS3-FA07-02 

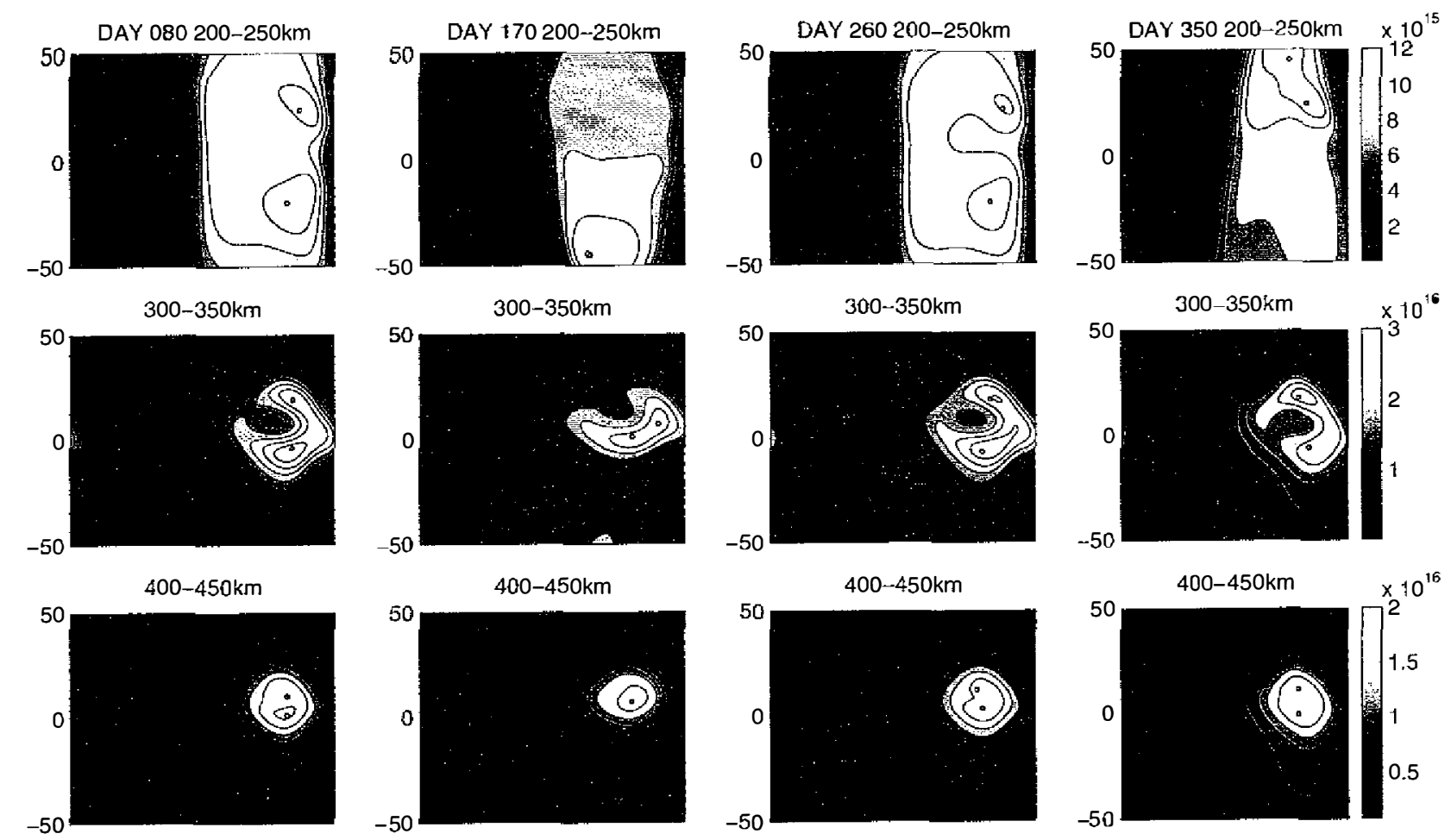

$\frac{2}{2}$
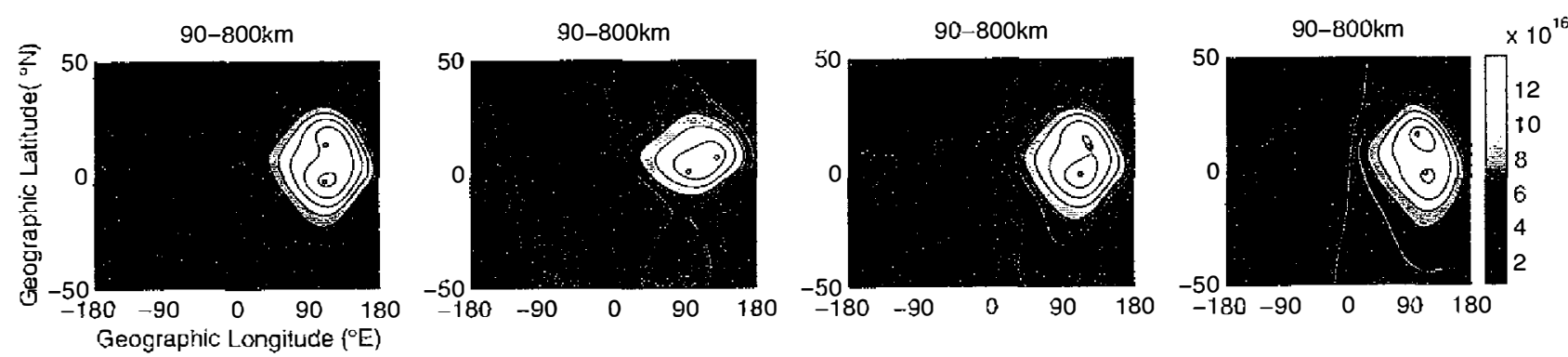

Fig. 10. The TEC MAPs in various altitude ranges and seasons during the solar minimum derived from the TIEGCM. 


\section{REFERENCES}

Budden, K. G., 1985: The Propagation of Radio Waves, Cambridge University Press, NY, $669 \mathrm{pp}$.

Davies, K., 1990: Ionospheric Radio, Peter Peregrinus Ltd., 580 pp.

Ezquer, R. G., N. O. Adler, S. M. Radicella, M. M. Gonzalez, and J. R. Manzano, 1992: Total electron content obtained from ionogram data alone. Radio Sci., 27, 429-434.

Fesen, C. G., r. g. Roble, and E. C. Ridley, 1991: Thermospheric tides at equinox: Simulations with coupled composition and auroral forcings, 2, Semidiurnal component. $J$. Geophys. Res., 96, 3663-3677.

Forbes, J. M., R. G. Roble, and C. G. Fesen, 1993: Acceleration, heating, and compositional mixing of the thermosphere due to upward propagating tides. J. Geophys. Res., 98, 311-321.

Hajj, G. A., L. C. Lee, X. Pi, L. J.Romans, W. S.Schreiner, P. R.Straus, and C. Wang, 2000: COSMIC GPS ionospheric sensing and space weather. TAO, 11, 235-272.

Hof mann-Wellenhof, B., H. Lichtenegger, and J. Collins, 1992: GPS theory and practice, Springer-Verlag, Wien, New York, 468 pp.

Jackson J. E., 1969: The reduction of Topside Ionograms to Electron-Density Profiles. Proc. IEEE, 57, 960-976.

Liu, J. Y., H. F. Tsai, and T. K. Jung, 1996: Total electron content obtained by using the global positioning system. Terr. Atmos. Oceanic Sci., 7, 107-117.

Reinisch, B. W., 1996: Modern ionosondes in Modern Ionospheric Science. In: Kohi et al. (Eds), European Geophysical Society, Katlenburg-Lindau, FRG, 440-458 pp.

Richmond, A. D., E. C. Ridley, and R. G. Roble, 1992: A thermosphere/ionosphere general circulation model with coupled electrodynamics. Geophys. Res. Lett., 19, 601-604.

Sardon, E., A. Rius, and N. Zarraoa, 1994: Estimation of the transmitter and receiver differential biases and the ionospheric total electron content from Global Positioning System observations. Radio Sci., 29, 577-586.

Titheridge, J. E., 1985: Ionogram analysis with the generalised program POLAN, World Data Center A for Solar-Terrestrial Physics, Report UAG-93.

Tsai, H. F., 1995: Total Electron Content Obtained by using the Global Positioning System, MS thesis, National Central University, Taiwan, ROC, 84 pp.

Tsai, L.-C., F. T. Berkey, and G. S. Stiles, 1995: The true-height analysis of ionograms using simplified numerical procedures. Radio Sci., 30 (4), 949-959.

Wilson, D. B., A. J. Mannucci, C. D. Edwards and T. Roth, 1992: Global ionospheric maps using a global network of GPS receivers, the International Beacon Satellite Symposium, MIT, Cambridge, MA, July 6-12.

Wu, S. L., 1992: Electron density profiles in Taiwan, MS thesis, National Central University, Taiwan, ROC, 83 pp. 